Journal of Engineering and Applied Sciences 14 (Special Issue 1): 3853-3856, 2019

ISSN: 1816-949X

(C) Medwell Journals, 2019

\title{
Finite Element Analysis and Optimization of Tyre Coupling using ANSYS Workbench Software
}

\author{
R. Praveenkumar \\ Department of Mechanical Engineering, AMET University, Chennai, India
}

\begin{abstract}
The point of the research is to model and examination the tyre coupling with a scope of material together with the existing material substitution and the physical and mechanical properties of the coupling which is utilized as a part of operation of draw in and separate of wheels tyre with the contact. The material utilized as existing in tire coupling is outlined and examination is surrendered out with correlation of proposed material. The results are plotted and talked about.
\end{abstract}

Key words: Finite element, optimization, tyre coupling, ANSYS and material, substitution, correlation

\section{INTRODUCTION}

The two essential tire-couplings vary by elastomeric material. The material contrasts are commonly elastic based components or urethane-based components (thermoset or thermoplastic elastomers). The general geometry and plan of each coupling fluctuates because of the impacts from the material sort and along these lines the disappointment modes are not indistinguishable. The disappointment modes clarified underneath are isolated, when proper, in light of the distinctions from modular proof. Note that mixes of these disappointment modes are normal and frequently related. With the end goal of this report, the accompanying modes and illustrations are self-governing and elite. Exhaustion is a part's common debilitating as a response to cyclic anxieties. The essential method of disappointment for tire couplings is weariness. As worries from torsion, arrangement, begin/stop, over-burdens as well as outward strengths follow up on the tire component, the component debilitates. Over the time of operation the component will fall flat. Weariness in urethane-based elastomers is confirmed by a tear of the component through the sidewall simply over the fortified region. This tear is ordinarily continuous. The disappointment proliferates from the finish of the component through the anxiety alleviation sorrows at the split. These disappointments can be identified ahead of schedule with visual review by watching the underlying break/tear of the coupling closes. The most well-known reason for weariness disappointment is impacted by misalignment. Weakness in elastic based elastomers is proving by breaks in the district of the component split. Be that as it may, the essential exhaustion harm is proving by expansive breaks found marginally over the cinch circle. These breaks amplify totally through the component and regularly radially over the outside width of the component. As the splits engender, elastic flotsam and jetsam, frequently like espresso beans will be obvious underneath the coupling. Substitution is prescribed when breaks stretch out for at least $20 \%$ of the component circuit. In the event that the component is not supplanted the breaks will proceed to engender and the fortification texture will end up plainly torn and uncovered. The texture strands are regularly developed and exposed.

McGinnity and Mancuso (2005), Berente et al. (2008) the existing work explains new pump coupling which reduces effects of torque, misalignment and unbalance. An introduction to efficiency management within an industrial environment and flexible couplings is described by Veale and Roberts (2011), Johnson (1996). Investigation on growth and characterization of 3-methoxy-4-hydroxy-benzaldehyde organic are in single crystals. Chemical and structural analysis of gallstones from the Indian subcontinent is discussed in the past work (Gandhimathi and Dhanasekaran, 2016; Ramya et al., 2017; Sagadevan et al., 2016, 2017; Fayaz et al., 2014). Fayaz et al. (2014) shows the assembly of bottom hole and mud motor for directional drilling experimental setup with analysis of gas flow behaviour in various economizer ducts. 3-methoxy-4-hydroxy-benzaldehyde organic single crystals growth and characterization is explained by Gandhimathi and Dhanasekaran (2016). A gallstone from the Indian subcontinent is studied with its chemical and structural analysis as given in this study (Ramya et al., 2017). $\mathrm{TiO}_{2}$ /graphene oxide nano-composite material is portrayed by Sagadevan et al. (2017) by the way of characterization. Investigations on synthesis, structural, surface morphological, optical and thermal properties of copper oxide nano-fluids are presented by Sagadevan et al. (2016). Mud Motor for directional drilling is explained (Fayaz et al., 2014) with bottom whole assembly.

The tyre coupling model is created by the design software which means the three dimensional model of the tyre coupling is created by the Solidworks Software. 


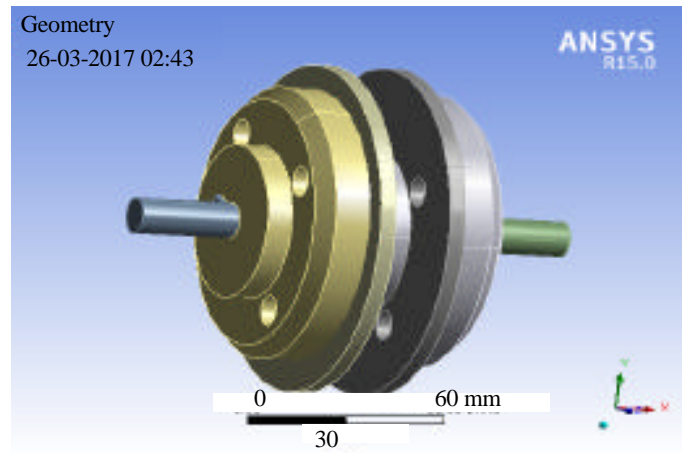

Fig. 1: Tyre coupling

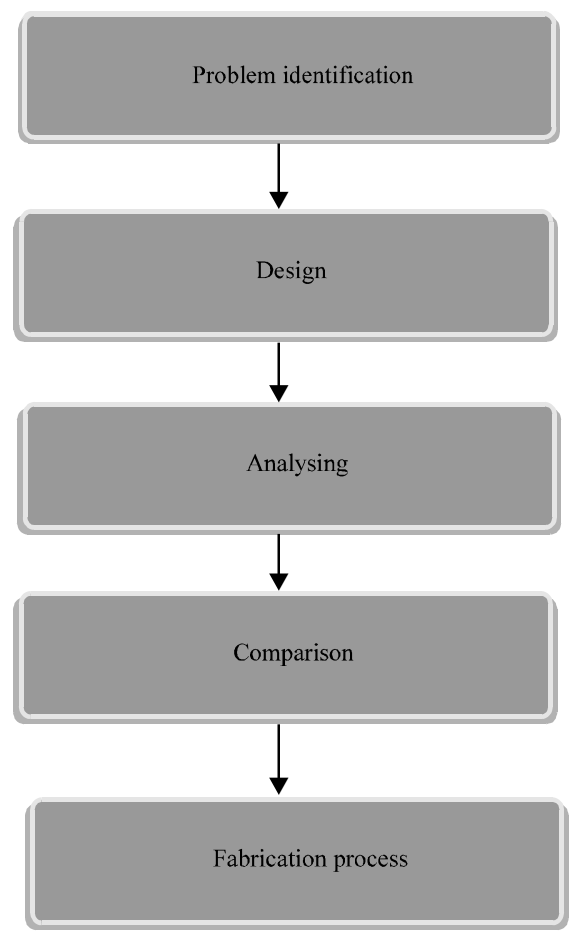

Fig. 2: Product making steps

This created model is converted to the step file for analysis the tyre coupling with various materials. The three dimensional model of the tyre coupling is shown in Fig. 1. Figure 2 shows the product making steps which is used in the industries. The flow chart includes design, analysis and checking.

\section{MATERIALS AND METHODS}

The tyre coupling model is created by the Solidworks Software. After the solid model creation we will select the material of the model. Material selection is important one for every component fabrication. In this study we will select various materials and also we analysis
Table 1: Existing properties of clutch plate

\begin{tabular}{ll}
\hline Properties & Values \\
\hline Volume & $120.35\left(\mathrm{~mm}^{3}\right)$ \\
Material & Cast iron \\
Co-ordinates type & Cartesian \\
Mass & $12.32 \mathrm{e}-003(\mathrm{~kg})$ \\
Nodes & 475 \\
Elements & 243 \\
\hline
\end{tabular}

Table 2: Properties of proposed material

\begin{tabular}{ll}
\hline Materials & Duplex iron \\
\hline Density & $2.58\left(\mathrm{~g} / \mathrm{cm}^{3}\right)$ \\
Yield strength & $35(\mathrm{MPa})$ \\
Compressive strength & $354(\mathrm{MPa})$ \\
Modulus of elasticity & $125(\mathrm{GPa})$ \\
Vickers hardness & 2531 \\
Thermal conductivity & 0.92 \\
\hline
\end{tabular}

the tyre coupling by its existing material. Finally the all results are compared with each other. Table 1 shows the existing material properties of the tyre coupling. Table 2 shows the proposed material properties for the tyre coupling.

The tyre coupling fabrication methodology is shown in the bellow flow chart. The first step is finding the problems in tyre coupling. After the problem identification, the tyre coupling model was designed by the Solidworks Software. The model was created for overcome the drawbacks of the existing tyre coupling. The created model was analysed by the ANSYS Workbench Software. After the analysis, the results of the existing model and results of the proposed models are compared with each other.

Structural analysis: The static structural analysis method is selected for analysis the tyre coupling. The results of the tyre coupling are shown in Fig. 3-5. Deformation is the important result in the analysis. The total deformation of tyre coupling is shown in Fig. 3. The maximum deformation value and minimum deformation value of the tyre coupling was indicated by the red colour and blue colour.

In the analysis, there are two different types of deformation are available. One is total deformation and another one is directional deformation. Directional deformation is known as the deformation of the component in the direction X-Z. Figure 4 shows the $Z$ directional deformation of the tyre coupling. The maximum $\mathrm{Z}$ directional deformation value is $2.63 \mathrm{e}-5 \mathrm{~mm}$.

Deformation is the important result in the analysis. Directional deformation is known as the deformation of the component in the direction X-Z. Figure 5 shows the $\mathrm{X}$ directional deformation of the tyre coupling. The maximum X directional deformation value is 1.2983 e- $6 \mathrm{~mm}$. 
J. Eng. Applied Sci., 14 (Special Issue 1): 3853-3856, 2019

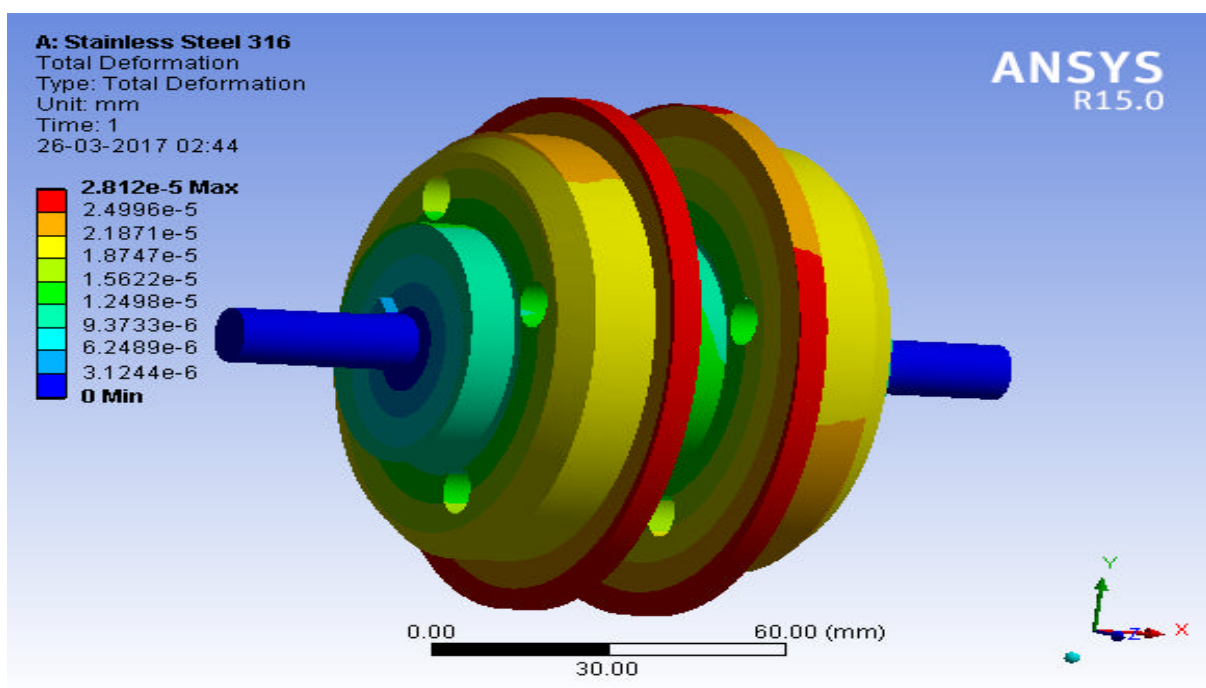

Fig. 3: Total deformation

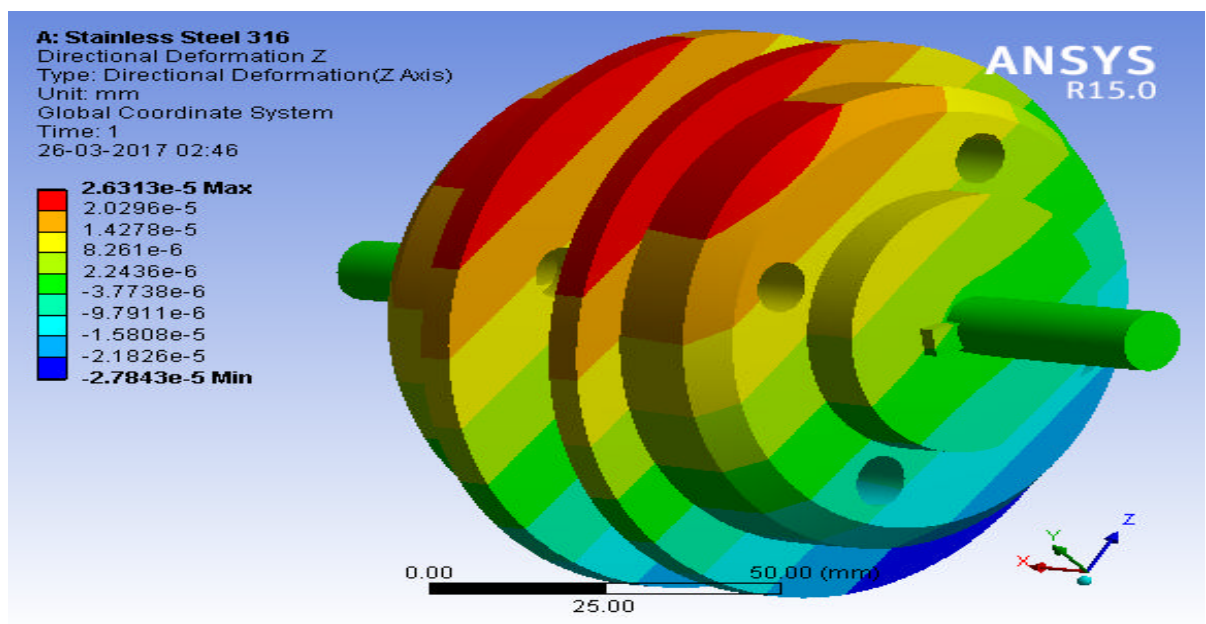

Fig. 4: Directional deformation z

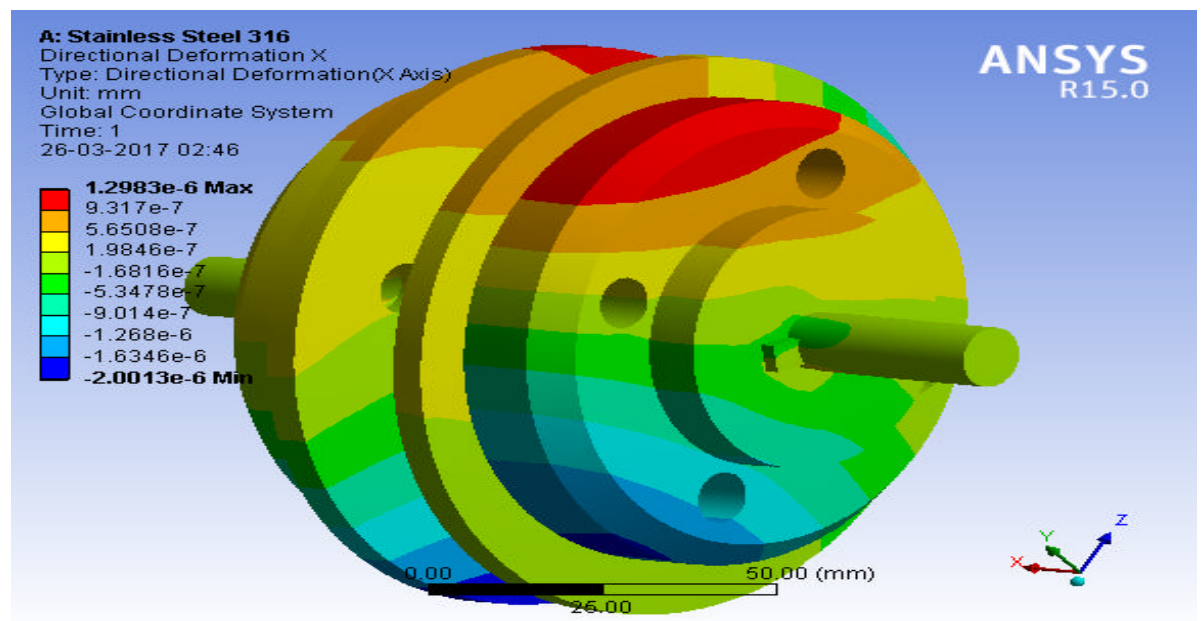

Fig. 5: Directional deformation $\mathrm{X}$ 
Table 3: Results

\begin{tabular}{lccc}
\hline Material & Stress & Displacement & Sliding contact \\
\hline Cast iron & 11.22 & $0.12 \mathrm{e}-3$ & $0.132 \mathrm{e}-5$ \\
Duplex iron & 8.52 & $0.23 \mathrm{e}-3$ & $0.189 \mathrm{e}-4$ \\
Stainless steel & 6.88 & $0.65 \mathrm{e}-3$ & $0.125 \mathrm{e}-4$ \\
\hline
\end{tabular}

\section{RESULTS AND DISCUSSION}

All the results of tyre coupling are noted in Table 3 for compare the values to other material results. The tyre coupling was analyzed by the different materials by using the ANSYS Workbench Software. The existing material cast iron has maximum stress as $11.22 \mathrm{MPa}$. The stainless steel material has minimum stress as $6.88 \mathrm{MPa}$. By the above analysis the proposed material stainless steel is safer than the existing material cast iron.

\section{CONCLUSION}

The tyre coupling solid model was successfully created by the Solidworks Software. The created model was successfully analyzed by the three different materials by the help of ANSYS Workbench Software. The three different materials are compared with each other. By the comparison stainless steel material gives better mechanical properties than the other two materials.

\section{REFERENCES}

Berente, N., Y. Yoo and K. Lyytinen, 2008. Alignment or drift? Loose coupling over time in NASA's ERP implementation. Proceedings of the 29th International Conference on Information Systems (ICIS), December 14-17, 2008, AIS Electronic Library (AISel), Paris, France, pp: 1-18.
Fayaz, B.A., A. Sunny and N. Nazeel, 2014. Bottom hole assembly and mud motor for directional drilling. Biosci. Biotechnol. Res. Asia, 11: 201-206.

Gandhimathi, R. and R. Dhanasekaran, 2016. Investigation on growth and characterization of 3-methoxy-4-hydroxy-benzaldehyde organic single crystals. Optoelectronics Adv. Mater. Rapid Commun., 10: 59-64.

Johnson, C.M., 1996. An introduction to flexible couplings. World Pumps, 1996: 38-43.

McGinnity, M. and J. Mancuso, 2005. New pump coupling reduces effects of torque, misalignment and unbalance. World Pumps, 2005: 34-37.

Ramya, J.R., K.T. Arul, M. Epple, U. Giebel and G.J. Guendel et al., 2017. Chemical and structural analysis of gallstones from the Indian subcontinent. Mater. Sci. Eng. C., 78: 878-885.

Sagadevan, S., K. Pal, P. Koteeswari and A. Subashini, 2017. Synthesis and characterization of TiO2-graphene oxide nanocomposite. J. Mater. Sci. Mater. Electron., 28: 1-7.

Sagadevan, S., R.S.A.S. Pichaikani and R. Sudhakar, 2016. Investigations on synthesis, structural, surface morphological, optical and thermal properties of copper oxide nanofluids. Thermal Sci., 20: S1197-S1202.

Veale, K.L. and L.W. Roberts, 2011. Efficiency management within an industrial environment. Proceedings of the 2011 IEEE 18th International Conference on Industrial Engineering and Engineering Management (IE\&EM'11), September 3-5, 2011, IEEE, Changchun, China, ISBN:978-1-61284-446-6, pp: 1859-1863. 